\title{
Pemilihan Departemen Terbaik dengan Metode Additive Ratio Assessment
}

\author{
Asep Supriatna ${ }^{\mathrm{a}, 1}$, Dedih $^{\mathrm{a}, 2, *}$ dan Yessy Yanitasari ${ }^{\mathrm{a}, 3}$ \\ a STMIK Kharisma Karawang, Jl. Pangkal Perjuangan Km. 1 Baypass, Karawang Jawa Barat 41316, Indonesia \\ ${ }^{1}$ Asepsupriatna0805199030@gmail.com; ${ }^{2}$ dedihthea@gmail.com; ${ }^{3}$ yessy.yanitasari@gmail.com \\ *corresponding author
}

\section{INFORMASI ARTIKEL ABSTRAK}

Dikirim : 11 November 2020

Diulas : 03 Desember 2020

Direvisi : 11 Desember 2020

Diterbitkan : 28 Desember 2020

Kata Kunci:

ARAS

Best Department

Decision Support System

Keywords:

ARAS

Best Department

Decision Support System
PT Djabesmen Lemah Abang adalah salah satu perusahaan yang mengadakan pemilihan departemen terbaik setiap tahunnya dengan menggunakan 5 kriteria yaitu ringkas, rapi, resik rawat serta rajin, kegiatan ini diikuti oleh 12 departemen yaitu accounting, planning and delivery, information and comunication tecnologies, purchasing, human resource, warehouse, quality asurance, technical and development, maintenance asbes cement, maintenance royalboard, quality asurance royalboard, Gudang spare part. Di dalam program tersebut penilaian masih mengunakan lembar cheklist yang di isi dan dihitung secara manual, jika terjadi adanya hasil penilaian sama tinggi antar departemen maka pimpinan perusahaan akan secara subjektif menentukan pemenangnya. Maka dengan itu dibutuhkan suatu sistem penunjang keputusan , adapun metode yang di pilih yaitu metode Additive Ratio Assessment (ARAS) dimana metode ini akan memilih semua kriteria berdasarkan nilai tertinggi atau nilai terendah untuk di hitung dari data alternatif yang sudah disediakan. Hasil penilaian dengan metode ARAS diperoleh bahwa bahwa nilai tertinggi adalah technical and development departement dengan nilai 1,0 dan nilai terendah adalah maintenance asbes cement department dengan nilai 0,56 .

\section{ABSTRACT}

PT Djabesmen Lemah Abang is one of the companies that selects the best department every year using 5 criteria, namely concise, neat, in-care and diligent, this activity is followed by 12 departments, namely accounting, planning and delivery, information, and communication technologies, purchasing, human resource, warehouse, quality assurance, technical and development, maintenance asbestos cement, maintenance royalboard, quality assurance royal board, spare part warehouse. In the program, the assessment still uses a checklist sheet that is filled in and calculated manually, if there is an equal assessment result between departments, the company leadership will subjectively determine the winner. So, with that we need a decision support system, while the method chosen is the Additive Ratio Assessment (ARAS) method where this method will select all criteria based on the highest or lowest value to be calculated from the alternative data that has been provided. The results of the assessment using the ARAS method show that the highest value is the technical and development department with a value of 1.0 and the lowest value is the maintenance of asbestos cement department with a value of 0.56 .

This is an open access article under the $\mathrm{CC}-\mathrm{BY}-\mathrm{SA}$ license. 


\section{Pendahuluan}

Program Ringkas, Rapi, Resik, Rawat dan Rajin (5R) adalah budaya untuk ditaati oleh semua pekerja dalam menciptakan tempat kerja yang tertata ringkas, tampak terlihat rapih, bersih dan tertib sehingga memudahkan perusahaan mencapai tujuan yang telah ditetapkan [1]. Penerapkan 5R dengan kesadaran akan pentingnya budaya 5R kapan saja dan dimana saja pada saat bekerja, akan lebih efisien dan terasa lebih mudah [2]. Ada beberapa perusahaan berlomba-lomba dalam program tersebut untuk mencari departemen yang memenuhi empat sasaran pokok yang akan dijadikan departemen terbaik. Didalam penilaian program 5R ada beberapa perusahaan menggunakan sistem penunjang keputusan untuk memberikan kemudahan dalam pengambilan keputusan. Sistem penunjang keputusan adalah suatu kumpulan dari bagian-bagian yang tidak terpisahkan yaitu pengetahuan, aplikasi untuk memecahkan suatu permasalahan sehingga menghasilkan sebuah alternatif keputusan [3], baik keputusan semi terstruktur maupun tidak terstruktur [4]. Sistem penunjang keputusan sudah digunakan dalam penentuan peluang usaha holtikultura [5] dan makanan yang tepat [6]. Sistem penunjang keputusan memiliki berbagai metode perhitungan salah satunya metode Additive Ratio Assessment (ARAS), yang mempunyai tujuan untuk memberi alternatif mendekati yang paling baik dari jumlah atribut dan peringkat akhir dari alternatif yang dibuat dengan menentukan tingkat utilitas setiap alternatif [7].

PT Djabesmen Lemah Abang adalah salah satu perusahaan yang mengadakan pemilihan departemen terbaik dalam program 5R untuk dilaksanakan tiap tahun, kegiatan ini diikuti oleh 12 departemen yaitu accounting, planning and delivery, information and comunication tecnologies, purchasing, human resource, warehouse, quality asurance, technical and development, maintenance asbes cement, maintenance royalboard, quality asurance royalboard, Gudang spare part. Di dalam program tersebut penilaian masih mengunakan lembar cheklist yang di isi dan dihitung secara manual, jika terjadi adanya hasil penilaian sama tinggi antar departemen maka pimpinan perusahaan akan secara subjektif menentukan pemenangnya. sehingga mengakibatkan terjadinya selisih pendapat antar departemen dalam hasil penilaian departemen terbaik sehingga berimbas pada berkurangnya kinerja karyawan. Dari penelitian sebelumnya Penerapan 5R dimulai dari tahap Ringkas, untuk memilah barang antara yang dibutuhkan atau tidak dibutuhkan, Rapi dimulai dari pemberian label barang dan tempat barang sehingga mudah ditemukan pada saat dibutuhkan, Resik adalah tempat kerja yang bersih, Rawat adalah kegiatan untuk mengelola sesuai dengan standar dan tahapan terakhir Rajin untuk diadakannya tim audit untuk mengaudit penerapan 5R pada perusahaan tersebut [2]. Perbaikan lingkungan kerja dengan menggunakan metode 5R berpengaruh terhadap motivasi kerja karyawan. Metode ARAS pada penelitian sebelumnya menyatakan hasil yang diperoleh pada nilai yang dimulai dari yang maximum sampai minimum yang disesuikan dengan hitungan data alternatif, pembobotan, nilai dominasi, preferensi dan nilai indeks [8]. Metode ARAS telah digunakan dalam pemilihan team leadershift terbaik [9], seleksi tenaga kerja [10], pemilihan asisten perkebunan terbaik [11], penilaian guru terbaik [12], pemilihan jaksa [13] dan pemilihan susu gym terbaik [14]. Berdasarkan penelitian sebelumnya maka metode ARAS dapat juga di implementasikan dalam pemilihan departemen terbaik dengan menggunakan 5 kriteria dan 12 alternatif yang ada di PT Djabesmen Lemah Abang.

\section{Metode}

Pertama kali tahun 2010 Zavadskas dan Turskis membuat Metode ARAS [15], yang bertujuan untuk memilih alternatif terbaik berdasarkan jumlah atribut dan peringkat akhir dari alternatif dibuat dengan menentukan tingkat utilitas setiap alternatif. Adapun tahapannya seperti dibawah ini.

A. Membentuk Decision Making Matrix persamaan (1)

Keterangan :

$$
X=\left|\begin{array}{rrrrr}
r_{01} & \ldots & r_{0 j} & \ldots & r_{0 n} \\
r_{i 1} & \ldots & r_{i j} & \ldots & r_{i n} \\
r_{m 1} & \ldots & r_{m j} & \ldots & r_{m n}
\end{array}\right| \quad(\mathrm{i}=0, \mathrm{~m} ; \ldots \mathrm{j}=1, \mathrm{n})
$$

$\mathrm{m} \quad=$ Nilai alternatif

$\mathrm{n} \quad=$ Nilai kriteria

$\mathrm{X}_{\mathrm{ij}} \quad=$ Jumlah dari alternatif $i$ pada kriteria $j$

$\mathrm{X}_{0 \mathrm{j}} \quad=$ Jumlah dari kriteria $j$

Apabila jumlah pada kriteria $j \mathrm{X}_{0 \mathrm{j}}$ belum diketahui, maka:

$$
\begin{aligned}
& \mathrm{X}_{0 \mathrm{j}}=\frac{\max }{1} \cdot \mathrm{X}_{\mathrm{ij}}, \text { if } \frac{\max }{1} \cdot X i j \text { is Benefit } \\
& \mathrm{X}_{0 \mathrm{j}}=\frac{\text { min }}{1} \cdot \mathrm{X}_{\mathrm{ij}} \text {, if } \frac{\text { min }}{1} \cdot X i j \text { is Cost }
\end{aligned}
$$


B. Normalisasi matriks keputusan pada setiap kriteria

Apabila kriteria keuntungan untuk dinormalisasi menggunakan persamaan (4).

$$
X_{i j}=\frac{X_{i j}}{\sum_{i=0}^{m} x_{i j}}
$$

$\mathrm{X}_{\mathrm{ij}}$ merupakan jumlah Normalisasi. Jika kriteria Biaya sehingga dilaksanakan normalisasi berikut:

$$
\begin{aligned}
& X_{i j}=\frac{1}{X_{i j}} \\
& R=\frac{X_{i j}}{\sum_{i=0}^{m} x_{i j}}
\end{aligned}
$$

C. Menetapkan bobot matriks yang telah dinormalisasi persamaan (7)

$$
\mathrm{D}=\left[\mathrm{D}_{\mathrm{ij}}\right] \mathrm{m} \cdot \mathrm{n}=\mathrm{R}_{\mathrm{ij}} \cdot \mathrm{W}_{\mathrm{j}}
$$

D. Menetapkan nilai dari fungsi optimalisasi (Si) persamaan (8)

$$
S_{i}=\sum_{j=0}^{n} D_{i j}(i=1,2 \ldots, m ; j=1,2 \ldots, n)
$$

Si merupakan jumlah fungsi optimalitasi alternatif $i$. Jumlah paling tinggi mencerminkan nilai paling bagus, dan jumlah terendah menggambarkan nilai yang sangat kurang.

E. Menentukan tingkatan peringkat tertinggi dari alternatif persamaan (9)

$$
K_{i}=\frac{S_{i}}{S_{o}}
$$

$S i$ dan $S 0$ adalah jumah kriteria optimalitas, $U i$ yang berkisar pada rentang dan diharapkan untuk ketepatan relatif kompleks pada alternatif memadai dan dapat ditetapkan pas pada nilai fungsi utilitas.

\section{Hasil dan Pembahasan}

Untuk menentukan departemen terbaik dalam program 5R, yang pertama adalah penentuan kriteria, bobot dan jenis. Adapun kriteria yang ditentukan yaitu ringkas, rapi, resik, rawat dan rajin. Pada penetapan bobot dari semua kriteria mempunyai sub-sub kriteria berlainan. Jumlah bobot ditetapkan bersumber informasi yang didapatkan didalam perusahaan yang sudah di bakukan. Berikut ini adalah nilai yang sudah diputuskan oleh perusahaan terlihat pada Tabel 1 .

Tabel 1 Kriteria, bobot dan jenis

\begin{tabular}{cclcl} 
No & Kriteria & Deskripsi & Bobot & \multicolumn{1}{c}{ Tipe } \\
\hline 1 & KR1 & Ringkas & 6 & Keuntungan \\
\hline 2 & KR2 & Rapi & 12 & Keuntungan \\
\hline 3 & KR3 & Resik & 12 & Keuntungan \\
\hline 4 & KR4 & Rawat & 15 & Biaya \\
\hline 5 & KR5 & Rajin & 6 & Keuntungan \\
\hline
\end{tabular}

Data alternatif terdiri dari 12 departemen yang akan dijadikan sebagai kandidat. Tabel 2 memperlihatkan data alterrnatif.

Tabel 2. Data alternatif

\begin{tabular}{ccl} 
No & Alternatif & \multicolumn{1}{c}{ Deskripsi } \\
\hline 1 & AL1 & Accounting \\
\hline 2 & AL2 & Planning and delivery \\
\hline 3 & AL3 & Purchasing \\
\hline 4 & AL4 & Information and comunication tecnologies \\
\hline 5 & AL5 & Human resource \\
\hline 6 & AL6 & Warehouse \\
\hline 7 & AL7 & Quality asurance royalboard \\
\hline 8 & AL8 & Technical and development \\
\hline 9 & AL9 & Maintenance asbes cement \\
\hline 10 & AL10 & Maintenance royalboard \\
\hline 11 & AL11 & Quality asurance royalboard \\
\hline 12 & AL12 & Gudang spare part
\end{tabular}


Adapun tahapan-tahapan metode ARAS adalah seperti berikut ini :

1. Pembentukan decision making matriks

Berdasarkan Tabel 1 dan Tabel 2 merujuk persamaan 1,2 dan 3 maka dibentuk Tabel 3 yang mana data pada semua alternatif merujuk dari nilai kriteria yang telah putuskan yaitu:

Tabel 3 Pembentukan Decision Making Matriks

\begin{tabular}{cccccc} 
Alternatif & KR1 & KR2 & KR3 & KR4 & KR5 \\
\hline AL1 & 6 & 12 & 12 & 15 & 6 \\
\hline AL2 & 6 & 12 & 12 & 15 & 6 \\
\hline AL3 & 5 & 11 & 11 & 13 & 5 \\
\hline AL4 & 6 & 11 & 10 & 11 & 5 \\
\hline AL5 & 6 & 11 & 10 & 11 & 5 \\
\hline AL6 & 5 & 11 & 11 & 13 & 6 \\
\hline AL7 & 5 & 12 & 10 & 15 & 6 \\
\hline AL8 & 6 & 12 & 6 & 6 & 5 \\
\hline AL9 & 5 & 10 & 11 & 14 & 4 \\
\hline AL10 & 6 & 12 & 12 & 14 & 3 \\
\hline AL11 & 6 & 12 & 12 & 11 & 6 \\
\hline AL12 & 6 & 11 & 11 & 15 & 5 \\
\hline Nilai Bobot Wj & 0.12 & 0.24 & 0.24 & 0.29 & 0.12 \\
\hline Nilai Total (Xmax) & 67 & 136 & 128 & 149 & 62 \\
\hline & & & & &
\end{tabular}

Bedasarkan tabel 3 maka dibuat matrik Xij berikut :

$$
\mathrm{X}_{\mathrm{ij}}=\left|\begin{array}{ccccc}
6 & 12 & 12 & 15 & 6 \\
6 & 12 & 12 & 15 & 6 \\
5 & 11 & 11 & 13 & 5 \\
6 & 11 & 10 & 11 & 5 \\
5 & 10 & 10 & 7 & 5 \\
5 & 11 & 11 & 13 & 6 \\
5 & 12 & 10 & 15 & 6 \\
6 & 12 & 6 & 6 & 5 \\
5 & 10 & 11 & 14 & 4 \\
6 & 12 & 12 & 14 & 3 \\
6 & 12 & 12 & 11 & 6 \\
6 & 11 & 11 & 15 & 5 \\
67 & 136 & 128 & 149 & 62
\end{array}\right|
$$

2. Penormalisasian matriks keputusan untuk semua kriteria

Berdasarkan persamaan 4, maka KR1 dapat di hitung yaitu :
$\mathrm{R}_{01}=\frac{6}{67}=0.08955$
$\mathrm{R}_{11}=\frac{6}{67}=0.08955$
$\mathrm{R}_{21}=\frac{5}{67}=0.07463$
$\mathrm{R}_{31}=\frac{6}{67}=0.08963$
$\mathrm{R}_{41}=\frac{5}{67}=0.07463$
$\mathrm{R}_{51}=\frac{5}{67}=0.07463$
$\mathrm{R}_{61}=\frac{5}{67}=0.07455$
$\mathrm{R}_{71}=\frac{6}{67}=0.08963$
$\mathrm{R}_{81}=\frac{6}{67}=0.0746$
$\mathrm{R}_{91}=\frac{6}{67}=0.0896$
$\mathrm{R}_{101}=\frac{6}{67}=0.0896$
$\mathrm{R}_{111}=\frac{6}{67}=0.0896$

Untuk perhitungan KR2, KR3 dan KR5 berdasarkan persamaan 4 dimana proses perhitungannya seperti KR1 sedang untuk perhitungan KR4 tahap 1 berdasarkan pada persamaan 5 dan perhitungan tahap 2 berdasarkan persamaan 6 :

KR4

Tahap 1
$\mathrm{X}_{04}=\frac{1}{15}=0.0667$
$\mathrm{X}_{14}=\frac{1}{15}=0.0667$
$\mathrm{X}_{24}=\frac{1}{13}=0.0769$
$\mathrm{X}_{34}=\frac{1}{11}=0.0909$
$\mathrm{X}_{44}=\frac{1}{7}=0.1429$
$\mathrm{X}_{54}=\frac{1}{13}=0.0769$
$\mathrm{X}_{64}=\frac{1}{13}=0.0667$
$\mathrm{X}_{74}=\frac{1}{6}=0.1667$ 


$$
\mathrm{X}_{84}=\frac{1}{14}=0.0714 \quad \mathrm{X}_{94}=\frac{1}{14}=0.0714 \quad \mathrm{X}_{104}=\frac{1}{11}=0.0909 \quad \mathrm{X}_{114}=\frac{1}{15}=0.0667
$$

Tahap 2

$$
\begin{aligned}
& \mathrm{R}_{04}=\frac{0.0667}{1.055}=0.0632 \quad \mathrm{R}_{14}=\frac{0.0667}{1.055}=0.0632 \quad \mathrm{R}_{24}=\frac{0.0769}{1.055}=0.0729 \quad \mathrm{R}_{34}=\frac{0.0909}{1.055}=0.0862 \\
& \mathrm{R}_{44}=\frac{0.1429}{1.055}=0.1354 \quad \mathrm{R}_{24}=\frac{0.0769}{1.055}=0.0729 \quad \mathrm{R}_{64}=\frac{0.0667}{1.055}=0.0632 \quad \mathrm{R}_{74}=\frac{0.1667}{1.055}=0.1580 \\
& \mathrm{R}_{84}=\frac{0.0714}{1.055}=0.0677 \quad \mathrm{R}_{94}=\frac{0.0714}{1.055}=0.0677 \quad \mathrm{R}_{104}=\frac{0.0909}{1.055}=0.0862 \quad \mathrm{R}_{114}=\frac{0.0667}{1.055}=0.0632
\end{aligned}
$$

Dari perhitungan setiap hasil diatas didapat matriks keputusan yang sudah dinormalisasikan yaitu :

$X^{*}=\left|\begin{array}{lllll}0.0896 & 0.0882 & 0.0938 & 0.0632 & 0.0968 \\ 0.0896 & 0.0882 & 0.0938 & 0.0632 & 0.0968 \\ 0.0746 & 0.0809 & 0.0859 & 0.0729 & 0.0806 \\ 0.0896 & 0.0809 & 0.0781 & 0.0862 & 0.0806 \\ 0.0746 & 0.0735 & 0.0781 & 0.1354 & 0.0806 \\ 0.0746 & 0.0809 & 0.0859 & 0.0729 & 0.0968 \\ 0.0746 & 0.0882 & 0.0781 & 0.0632 & 0.0968 \\ 0.0896 & 0.0882 & 0.0469 & 0.1580 & 0.0806 \\ 0.0746 & 0.0735 & 0.0859 & 0.0677 & 0.0645 \\ 0.0896 & 0.0882 & 0.0938 & 0.0677 & 0.0484 \\ 0.0896 & 0.0882 & 0.0938 & 0.0862 & 0.0968 \\ 0.0896 & 0.0809 & 0.0859 & 0.0632 & 0.0806\end{array}\right|$

3. Menentukan bobot matriks yang sudah dinormalisasi

Berdasarkan persamaan 7 maka ditetapkan bobot matrik yang telah dinormalisasi seperti berikut :

$\mathrm{D}_{01}=\mathrm{X}_{01} \times \mathrm{W}_{1}=0.0896 \times 0.12=0.0107$
$\mathrm{D}_{11}=\mathrm{X}_{11} \times \mathrm{W}_{1}=0.0896 \times 0.12=0.0107$
$\mathrm{D}_{21}=\mathrm{X}_{21} \times \mathrm{W}_{1}=0.0746 \times 0.12=0.0090$
$\mathrm{D}_{31}=\mathrm{X}_{31} \times \mathrm{W}_{1}=0.0896 \times 0.12=0.0107$
$\mathrm{D}_{41}=\mathrm{X}_{41} \times \mathrm{W}_{1}=0.0746 \times 0.12=0.0090$
$\mathrm{D}_{51}=\mathrm{X}_{51} \times \mathrm{W}_{1}=0.0746 \times 0.12=0.0090$
$\mathrm{D}_{61}=\mathrm{X}_{61} \times \mathrm{W}_{1}=0.0746 \times 0.12=0.0090$
$\mathrm{D}_{71}=\mathrm{X}_{71} \times \mathrm{WW}_{1}=0.0896 \times 0.12=0.0107$
$\mathrm{D}_{81}=\mathrm{X}_{81} \times \mathrm{W}_{1}=0.0746 \times 0.12=0.0090$
$\mathrm{D}_{91}=\mathrm{X}_{91} \times \mathrm{W}_{1}=0.0896 \times 0.12=0.0107$
$\mathrm{D}_{101}=\mathrm{X}_{101} \times \mathrm{W}_{1}=0.0896 \times 0.12=0.0107$
$\mathrm{D}_{111}=\mathrm{X}_{111} \times \mathrm{W}_{1}=0.0896 \times 0.12=0.0107$

Sedangkan untuk perhitungan $D_{02}, D_{03}, D_{04}$ dan $D_{05}$ prosesnya sama seperti $D_{01}$, Dari perhitungan hasil yang dinormalisasikan terhadap bobot kriteria diatas dapat hasil matriks berikut:

$\mathrm{D}=\left|\begin{array}{lllll}0.0107 & 0.0212 & 0.0225 & 0.0183 & 0.0116 \\ 0.0107 & 0.0212 & 0.0225 & 0.0183 & 0.0116 \\ 0.0090 & 0.0194 & 0.0206 & 0.0212 & 0.0097 \\ 0.0107 & 0.0194 & 0.0188 & 0.0250 & 0.0097 \\ 0.0090 & 0.0176 & 0.0188 & 0.0393 & 0.0097 \\ 0.0090 & 0.0194 & 0.0206 & 0.0212 & 0.0116 \\ 0.0090 & 0.0212 & 0.0188 & 0.0183 & 0.0116\end{array}\right|$




\begin{tabular}{|lllll}
0.0107 & 0.0212 & 0.0113 & 0.0458 & 0.0097 \\
0.0090 & 0.0176 & 0.0206 & 0.0196 & 0.0077 \\
0.0107 & 0.0212 & 0.0255 & 0.0196 & 0.0058 \\
0.0107 & 0.0212 & 0.0255 & 0.0250 & 0.0116 \\
0.0107 & 0.0194 & 0.0206 & 0.0183 & 0.0097
\end{tabular} \mid

4. Menentukan nilai dari fungsi optimalisasi $\left(\mathrm{S}_{\mathrm{i}}\right)$

Berdasarkan persamaan 8 maka $\mathrm{S}_{\mathrm{i}}$ dapat dihitung yaitu :

$\begin{array}{ll}\mathrm{S}_{1}=0.0107+0.0212+0.0225+0.0183+0.0116 & =0.084 \\ \mathrm{~S}_{2}=0.0107+0.0212+0.0225+0.0183+0.0116 & =0.084 \\ \mathrm{~S}_{3}=0.0090+0.0194+0.0206+0.0212+0.0097 & =0.080 \\ \mathrm{~S}_{4}=0.0107+0.0194+0.0188+0.0250+0.0097 & =0.084 \\ \mathrm{~S}_{5}=0.0090+0.0176+0.0188+0.0393+0.0097 & =0.094 \\ \mathrm{~S}_{6}=0.0090+0.0194+0.0206+0.0212+0.0116 & =0.082 \\ \mathrm{~S}_{7}=0.0090+0.0212+0.0188+0.0183+0.0116 & =0.079 \\ \mathrm{~S}_{8}=0.0107+0.0212+0.0113+0.0458+0.0097 & =0.099 \\ \mathrm{~S}_{9}=0.0090+0.0176+0.0206+0.0196+0.0077 & =0.075 \\ \mathrm{~S}_{10}=0.0107+0.0212+0.0255+0.0196+0.0058 & =0.080 \\ \mathrm{~S}_{11}=0.0107+0.0212+0.0255+0.0250+0.0116 & =0.091 \\ \mathrm{~S}_{12}=0.0107+0.0194+0.0206+0.0183+0.0097 & =0.079\end{array}$

Nilai Max Optimalisasi $\left(\mathrm{S}_{\mathrm{i}}\right)$ adalah 0.099

5. Menentukan tingkatan peringkat tertinggi dari alternatif

Berdasarkan persamaan 9 maka kita dapat menetapkan nilai $K_{i}$ seperti berikut :

$\mathrm{K}_{1}=0.084: 0.099=0.85$

$\mathrm{K}_{2}=0.084: 0.099=0.85$

$\mathrm{K}_{3}=0.080: 0.099=0.81$

$\mathrm{K}_{4}=0.084: 0.099=0.85$

$\mathrm{K}_{5}=0.094: 0.099=0.96$

$\mathrm{K}_{6}=0.082: 0.099=0.83$

$\mathrm{K}_{7}=0.079: 0.099=0.80$

$\mathrm{K}_{8}=0.099: 0.099=1.00$

$\mathrm{K}_{9}=0.075: 0.099=0.76$

$\mathrm{K}_{10}=0.080: 0.099=0.81$

$\mathrm{K}_{11}=0.091: 0.099=0.92$

$\mathrm{K}_{12}=0.079: 0.099=0.80$

Hasil dari perhitungan mendapatkan hasil peringkat (perengkingan) sebagai berikut:

Tabel 4 Hasil Perhitungan Metode ARAS

\begin{tabular}{llcc}
\multicolumn{1}{c}{ Alternatif } & \multicolumn{1}{c}{ Nama Departemen } & Nilai $\mathbf{K}_{\mathbf{I}}$ & Peringkat \\
\hline AL8 & Technical and development & 1.00 & 1 \\
\hline AL5 & Human resource & 0.96 & 2 \\
\hline AL11 & Quality asurance royalboard & 0.92 & 3 \\
\hline AL1 & Accounting & 0.85 & 4 \\
\hline AL2 & Planning and delivery & 0.85 & 5 \\
\hline AL4 & Information and comunication tecnologies & 0.85 & 7 \\
\hline AL6 & Warehouse & 0.83 & 8 \\
\hline AL10 & Maintenance royalboard & 0.81 & 9 \\
\hline AL3 & Purchasing & 0.81 & 10 \\
\hline AL7 & Quality asurance royalboard & 0.80 & 11 \\
\hline AL12 & Gudang spare part & 0.80 & 12 \\
\hline AL9 & Maintenance asbes cement & 0.76 & \multirow{2}{*}{} \\
\hline
\end{tabular}


Berdasarkan tabel 4 hasil perhitungan metode ARAS maka yang menjadi kandidat departemen terbaik adalah Technical and development dengan nilai 1.00 lalu urutan ke dua yaitu Human resource yang mendapat nilai 0,96 selanjutnya juara tiga didapat oleh Quality asurance royalboard dengan nilai 0,92 terus peringkat empat diperoleh Accounting dengan nilai 0,85 diteruskan peringkat ke lima oleh Planning and delivery dengan nilai 0,85 dan peringkat ke enam didapat oleh Information and comunication tecnologies dengan nilai 0,85 . Ada 3 departemen yang mendapat nilai yang sama tapi sistem langsung mengurutkan berdasarkan bobot kriteria masing-masing departemen. Selanjutnya peringkat ke tujuh diperoleh Warehouse dengan nilai 0,83 lalu untuk peringkat ke delapan didapat oleh Maintenance royalboard dengan nilai 0,81 dan urutan ke sembilan oleh Puchasing dengan nilai 0,81 selanjutnya urutan ke sepuluh diraih Quality asurance royalboard dengan poin 0,80 dan posisi ke sebelas oleh Gudang spare part dengan nilai 0,80 sedangkan posisi terakhir adalah Maintenance asbes cement dengan poin 0,76.

\section{Kesimpulan}

Pemilihan departemen terbaik dengan kriteria ringkas, rapi, resik, rawat dan rajin dapat dilakukan menggunakan metode ARAS dengan hasil nilai tertinggi yaitu departemen Technical and development dengan nilai 1 dan nilai paling rendah didapat oleh departemen Maintenance asbes cement dengan nilai 0,76.

\section{Ucapan Terima Kasih}

Pertama ucapan penghargaan kami tujukan kepada STMIK Kharisma Karawang serta PT Djabesmen lemah abang yang telah memberikan peluang dan kerjasama dalam penyediaan data untuk penelitian ini dan rekanrekan yang telah membantu selesainya penelitian ini.

[1] J. Issa, "Perbaikan Lingkungan Kerja Melalui Penerapan 5R Pengaruhnya Terhadap Motivasi Kerja Karyawan PT IMP," Perbaikan Lingkung. Kerja Melalui Penerapan 5R Pengaruhnya Terhadap Motiv. Kerja Karyawan PT IMP, vol. 5, no. 1, pp. 57-65, 2020.

[2] N. P. Kurniawati, “Analisis Penerapan Metode 5S Pada Warehouse Fast Moving PT. Indonesia Power Ubp Mrica Kabupaten Banjarnegara,” Performa Media Ilm. Tek. Ind., vol. 18, no. 1, pp. 2833, 2019, doi: 10.20961/performa.18.1.19078.

[3] R. H. Bonczek, C. W. Holsapple, and A. B. Whinston, "the Evolving Roles of Models in Decision Support Systems,” Decis. Sci., vol. 11, no. 2, pp. 337-356, 1980, doi: 10.1111/j.15405915.1980.tb01143.x.

[4] E. Turban, J. E. Aronson, and T. Liang, Decision Support Systems and Intelligent Systems, 7th ed. New Delhi: Prentice Hall Of India, 2005.

[5] Yogi Hermawan, . D., and Yessy Yanitasari, "Penentuan Peluang Usaha Pertanian Holtikultura Menggunakan Simple Additive Weighting dan Promethee,” J. RESTI (Rekayasa Sist. dan Teknol. Informasi), vol. 3, no. 3, pp. 422-428, 2019, doi: 10.29207/resti.v3i3.1255.

[6] E. Ningsih, "Sistem Pendukung Keputusan Menentukan Peluang Usaha Makanan yang Tepat Menggunakan Weighted Product(WP) Berbasis Web," vol. 9, pp. 244-254, 2017.

[7] D. Karabasevic, D. Stanujkic, and S. Urosevic, "The MCDM Model for Personnel Selection Based on SWARA and ARAS Methods," Manag. - J. theory Pract. Manag., vol. 20, no. 77, pp. 43-52, 2015, doi: 10.7595/management.fon.2015.0029.

[8] R. Fachrizal, "Implementasi ARAS ( Additive Ratio Assessment ) Dalam Pemilihan Kasir Terbaik," in Implementasi ARAS (Additive Ratio Assessment) Dalam Pemilihan Kasir Terbaik Studi Kasus Outlet Cardinal Store Plaza Medan Fair Rachmad, 2019, no. Januari, pp. 501-510.

[9] N. A. H. Lia Ciky Lumban Gaol, "Sistem Pendukung Keputusan Pemilihan Team Leader Shift Terbaik Dengan Menggunakan Metode ARAS," Inf. dan Teknol. Ilm., vol. 13, no. 1, pp. 16-21, 2018.

[10] N. A. H. Tetty Rosmaria Sitompul, "Sistem Pendukung Keputusan Seleksi Tenaga Kerja Untuk Security Service Menggunakan Metode Aras," J. Media Inform. Budidarma, vol. 2, no. 1, pp. 1-9, 2018, doi: 10.30865/mib.v2i1.812.

[11] R. S. Fadila Pratiwi, Fince Tinus Waruwu, Dito Putro Utomo, "Penerapan Metode Aras Dalam Pemilihan Asisten Perkebunan Terbaik Pada PTPN V Fadila," in Penerapan Metode Aras Dalam Pemilihan Asisten Perkebunan Terbaik Pada PTPN V Fadila, 2019, pp. 651-662.

[12] A. S. Nadeak, "Penerapan Metode Aras (Additive Ratio Assessment ) Dalam Penilaian Guru Terbaik," in Seminar Nasional Teknologi Komputer \& Sains (SAINTEKS), 2019, vol. 2, no. 2010, pp. 571-578.

[13] R. K. Ndruru, "Penerapan Metode Additive Ratio Assessment (ARAS) dan Rank Order Centroid (ROC) Dalam Pemilihan Jaksa Terbaik Pada Kejaksaan Negeri Medan," in Penerapan Metode Additive Ratio Assessment (ARAS) dan Rank Order Centroid (ROC) Dalam Pemilihan Jaksa Terbaik 
Pada Kejaksaan Negeri Medan Radius, 2020, pp. 367-372.

[14] H. Susanto, "Penerapan Metode Additive Ratio Assessment(Aras) Dalam Pendukung Keputusan Pemilihan Susu Gym Terbaik Untuk Menambah Masa Otot," Maj. Ilm. INTI, vol. 5, no. 2, pp. 86-90, 2018.

[15] E. K. Zavadskas and Z. Turskis, "A new additive ratio assessment (ARAS) method in multicriteria decision-making," Technol. Econ. Dev. Econ., vol. 16, no. 2, pp. 159-172, 2010, doi: 10.3846/tede.2010.10. 